\title{
Hepatitis B Core-Related Antigen: A Serum Biomarker for Intrahepatic Covalently-Closed-Circular DNA
}

\author{
Gian P. Caviglia ${ }^{1}$, Rinaldo Pellicano ${ }^{2}$, Giorgio M. Saracco ${ }^{1,2}$, Antonina Smedile ${ }^{1,2}$ \\ ${ }^{1}$ Department of Medical Sciences, University of Turin, Turin, Italy \\ ${ }^{2}$ Unit of Gastroenterology and Hepatology, Città della Salute e della Scienza, Molinette Hospital, Turin, Italy
}

(Clin. Lab. 2018;64:411-412. DOI: 10.7754/Clin.Lab.2017.171009)

\author{
Correspondence: \\ Gian Paolo Caviglia \\ Department of Medical Sciences \\ University of Turin \\ 10100 Turin \\ Italy \\ Phone: $\quad+390116333922$ \\ Fax: $\quad+390116333976$ \\ Email: caviglia.giampi@libero.it
}

\section{KEY WORDS}

antiviral treatment, biomarker, covalently-closedcircular DNA, hepatitis B core-related antigen, hepatitis $\mathrm{B}$ virus

\section{LETTER TO THE EDITOR}

Hepatitis B virus (HBV) infection is a major public health problem affecting more than 250 million people globally. Chronic hepatitis B (CHB) is a result of an acute, unresolved infection, that, overtime, may lead to cirrhosis and its complications such as liver failure and hepatocellular carcinoma [1]. In the last 15 years, several inhibitors of HBV polymerase, namely nucleos(t)ide analogues (NAs), have been developed and introduced in clinical practice, allowing long term suppression of HBV replication (virological response) and alanine aminotransferase (ALT) normalization (biochemical response) [2]. Hepatitis B surface antigen (HBsAg) loss and seroconversion to anti-HBs has been traditionally considered the final goal of antiviral treatment (functional cure). However, a complete cure could be achieved only with the physical elimination of HBV covalently-closed-circular DNA (cccDNA) which acts as template for all viral transcriptions and is responsible for long lasting viral persistence [3]. Currently, novel approaches aiming at HBV cccDNA elimination or inactivation are under evaluation at a preclinical level [3]. However, the possibility to measure intrahepatic HBV cccDNA is limited by liver biopsy availability and the lack of sensitive standardized PCR methods.

Hepatitis B core-related antigen (HBcrAg) is a novel serum biomarker combining the antigenic reactivity resulting from hepatitis $\mathrm{B}$ e antigen ( $\mathrm{HBeAg}), \mathrm{HBV}$ core 
antigen, and a $22 \mathrm{kDa}$ core-related protein (p22cr) mainly found in HBV empty particles [4,5]. It has been reported that HBcrAg levels varied significantly among the four natural phases of $\mathrm{HBV}$ infection showing high predictive performance for distinguishing between $\mathrm{HBe} \mathrm{Ag}$-negative inactive/quiescent carrier and $\mathrm{HBeAg-}$ negative hepatitis-patients (area under the curve [AUC] $=0.931$ ) and for the discrimination between immune tolerant and immune clearance phases $(\mathrm{AUC}=0.704)$ [6].

Interestingly, a significant correlation between HBcrAg and intrahepatic HBV cccDNA has been reported [7-9]. Suzuki et al., investigating the correlation between HBcrAg and intrahepatic HBV cccDNA in a cohort of Japanese CHB patients, found a positive correlation between the two parameters $(r=0.692, p<0.001)$. In addition, a significant correlation between HBcrAg and intrahepatic HBV cccDNA was also observed in patients that experienced HBsAg negativization $(\mathrm{r}=0.482$, $\mathrm{p}=0.006$ ), suggesting a potential role of HBcrAg also in subjects with occult HBV infection [7]. More recently, Matsuzaki et al. also reported a correlation between HBcrAg and HBV cccDNA levels $(r=0.616$, $\mathrm{p}<0.001)$ in patients undergoing liver transplant [8]. After excluding preoperative state samples from analysis, HBcrAg remained significantly correlated to $\mathrm{HBV}$ cccDNA $(r=0.402, p=0.046)$. Furthermore, HBcrAg and HBV cccDNA values showed similar kinetics during pre- and post-transplantation, highlighting HBcrAg reliability as a surrogate biomarker for HBV cccDNA [8]. Finally, a large-scale study including 305 liver biopsies and corresponding serum samples collected from 138 NAs-treated patients pointed out a median HBcrAg reduction at $\geq 6$ years of therapy comparable to the magnitude of HBV cccDNA decay [9]. HBcrAg was strongly correlated with intrahepatic $\mathrm{HBV}$ cccDNA $(\mathrm{r}=0.70, \mathrm{p}<0.0001)$. According to HBeAg status, HBcrAg was significantly correlated to HBV cccDNA levels both in the $133 \mathrm{HBeAg}$-positive patients $(\mathrm{r}=0.66, \mathrm{p}<0.0001)$ and in the 172 -negative patients $(\mathrm{r}=0.45, \mathrm{p}<0.0001)$. Moreover, analyzing 130 samples of HBV DNA-negative patients receiving antiviral therapy, authors observed that HBcrAg was still detectable in 101 of them, being significantly correlated with HBV cccDNA levels $(r=0.42, p<0.0001)$ [8].

\section{CONCLUSION}

Since the quantification of HBV cccDNA levels will be important in clinical trials evaluating novel treatment concepts to cure HBV infection, its relationship with HBcrAg quantification renders the latter a reliable noninvasive approach useful for monitoring intrahepatic virological status.

\section{Declaration of Interest:}

All authors have nothing to disclose regarding the material discussed in the present manuscript.

\section{References:}

1. Petrini E, Caviglia GP, Abate ML, Fagoonee S, Smedile A, Pellicano R. MicroRNAs in HBV-related hepatocellular carcinoma: functions and potential clinical applications. Panminerva Med 2015;57:201-9 (PMID: 25897630).

2. Caviglia GP, Abate ML, Pellicano R, Smedile A. Chronic heaptitis B therapy: available drugs and treatment guidelines. Minerva Gastroenterol Dietol 2015;61:61-70 (PMID: 25323305).

3. Durantel D, Zoulim F. New antiviral targets for innovative treatment concepts for hepatitis B virus and hepatitis delta virus. J Hepatol 2016;64:S117-S131 (PMID: 27084032).

4. Caviglia GP, Abate ML, Noviello D, et al. Hepatitis B core-related antigen kinetics in chronic hepatitis B virus genotype D-infected patients treated with nucleos(t)ide analogues or pegylated-interferon- $\alpha$. Hepatol Res 2017;47:747-54 (PMID: 27577976).

5. Caviglia GP, Smedile A. Hepatitis B core-related antigen: a novel biomarker for chronic hepatitis B treatment. Minerva Gastroenterol Dietol 2017;63:169-71 (PMID: 28673069).

6. Gou Y, Zhao Y, Rao C, et al. Predictive Value of Hepatitis B Core-Related Antigen (HBcrAg) During the Natural History of Hepatitis B Virus Infection. Clin Lab 2017;63:1063-70 (PMID: 28792701).

7. Suzuki F, Miyakoshi H, Kobayashi M, Kumada H. Correlation between serum hepatitis $\mathrm{B}$ virus core-related antigen and intrahepatic covalently closed circular DNA in chronic hepatitis B patients. J Med Virol 2009;81:27-33 (PMID: 19031469).

8. Matsuzaki T, Tatsuki I, Otani M, et al. Significance of hepatitis B virus core-related antigen and covalently closed circular DNA levels as markers of hepatitis B virus re-infection after liver transplantation. J Gastroenterol Hepatol 2013;28:1217-22 (PMID: 234 32697).

9. Wong DK, Seto Wk, Cheung CK, et al. Hepatitis B virus corerelated antigen as a surrogate marker for covalently closed circular DNA. Liver Int 2017;37:995-1001 (PMID: 27992681). 